\title{
Comércio de varejo de substâncias psicoativas ilícitas: sentidos de sua prática criminalização seletiva
}

DOI: 10.15175/1984-2503-202113207

\author{
Gusthavo Ribeiro Bacellar \\ Márcia Barros Ferreira Rodrigues ${ }^{* *}$
}

\begin{abstract}
Resumo
Este artigo discute os diversos sentidos da prática do comércio de substâncias psicoativas ilícitas a partir da análise de relatos obtidos em entrevistas semiestruturadas com autores destas práticas e residentes na Grande Vitória/ES e na cidade de Piúma/ES. Ao entrevistar condenados por tráfico de drogas que se encontravam, no momento das entrevistas, em cumprimento de pena em regime aberto, após certo período de aprisionamento, percebeu-se que os entrevistados optaram por recorrer a tais comportamentos pelas mesmas razões que levam qualquer jovem a ingressar em atividades formais de obtenção de renda que, entretanto, não se encontravam disponíveis para este grupo, discutimos a respeito da desproporcionalidade do atual formato de tratamento, pelo Estado, do problema do comércio de substâncias ilícitas, cujo formato, inclusive, se adaptou ao contexto da pandemia COVID-19, ampliando-se o modo delivery.
\end{abstract}

Palavras-chave: comércio de drogas; criminalização seletiva; encarceramento em massa.

El negocio de la venta de sustancias psicoactivas ilegales: los motivos de su criminalización selectiva práctica

\section{Resumen}

Este artículo discute los diversos motivos que llevan a la práctica del comercio al por menor de sustancias psicoactivas ilegales a partir del análisis de relatos obtenidos en entrevistas semiestructuradas con autores de estas prácticas residentes en Grande Vitória (Espírito Santo) y en la ciudad de Piúma (Espírito Santo). Al entrevistar a los condenados por narcotráfico que, en el momento de las entrevistas, estaban cumpliendo condena en régimen abierto tras un determinado periodo de encarcelamiento, se percibió que dichas personas optaron por recurrir a este tipo de actividades por las mismas razones que llevan a cualquier joven a realizar trabajos formales para obtener ingresos (un tipo de empleo que no era accesible a este grupo de personas). Paralelamente, se analizó la desproporcionalidad con la que en la actualidad el Estado trata el problema del

\footnotetext{
* Promotor de justiça Ministério Público do Espírito Santo (MPES). Bacharel em Direito pela Universidade Federal da Bahia; bacharel e mestre em Ciências Sociais pela Universidade Federal do Espírito Santo (UFES). E-mail: gusthavobacellar@hotmail.com. http://lattes.cnpq.br/1262864416058483.

(1) https://orcid.org/0000-0003-3697-5777

${ }^{*}$ Professora Titular do Departamento de Ciências Sociais da Universidade Federal do Espírito Santo (UFES). Doutora em História Social pela USP - Universidade de São Paulo (2000). Especialista em Sociologia Política pela Pontifícia Universidade Católica do Rio de Janeiro. Graduação em Ciências Sociais pela Universidade Federal Fluminense. Dois Pós-doutorados em Ciência Política na Universidade Federal Fluminense - UFF e Coordenadora Geral do NEI - Núcleo de Estudos Indiciários. E-mail: mbfrodrigues@gmail.com.

http://lattes.cnpq.br/1531744628299485. ㄴ https://orcid.org/0000-0002-6022-3041
} 
comercio de sustancias ilegales, un negocio que ha sido incluso capaz de adaptarse al contexto de la pandemia de la COVID-19 al ampliarse y efectuarse en modalidad de entrega a domicilio.

Palabras clave: narcotráfico; criminalización selectiva; encarcelamiento masivo.

\title{
Retail trade of illicit psychoactive substances: aspects of the practice's selective criminalization
}

\begin{abstract}
The following article discusses various aspects of the trade of illicit psychoactive substances based on an analysis of reports obtained in semi-structured interviews with perpetrators of these practices and residents in the Greater Vitória region and the city of Piúma, both in the Brazilian state of Espírito Santo. By interviewing individuals condemned for drug trafficking, who found themselves at the time of the interviews serving time in an open scheme after a certain period of imprisonment, it was observed that they tended to return to such behavior for the same reasons that lead any young person to become involved in formal activities for generating income, which were, however, not available to this group. We discuss the disproportionality of the State's current treatment method and the problem of the trade of illicit substances, whose format has also adapted to the COVID-19 pandemic, expanding to encompass the delivery model.
\end{abstract}

Keywords: drug trade; selective criminalization; mass incarceration.

\section{Commerce de détail de substances psychoactives illicites: signification de sa} criminalisation sélective

\section{Résumé}

Cet article débat des diverses significations de la pratique du commerce de substances psychoactives illicites à partir de l'analyse de témoignages issus d'entretiens semi-structurés avec des auteurs de telles pratiques résidant dans la région métropolitaine de Vitória et de Piúma, dans l'État brésilien de Espírito Santo. En interrogeant des condamnés pour trafic de stupéfiants qui purgeait, à l'occasion de l'entretien, leur peine en liberté conditionnelle après une période d'incarcération, nous avons pu constater que ces personnes avaient choisi de tels comportements pour les mêmes raisons qui amènent n'importe quel jeune à s'engager dans des activités formelles d'obtention de revenus, lesquelles ne se trouvaient néanmoins pas à leur disposition. Nous débattrons ainsi de la non-proportionnalité du format actuel de traitement par l'État du problème du commerce de substances illicites, qui s'est lui-même adapté au contexte de la pandémie de COVID-19 avec la généralisation de la livraison à domicile.

Mots-clés : commerce de stupéfiants ; criminalisation sélective ; incarcération de masse.

\section{巴西的毒品零售交易：其意义与选择性定罪}

\section{摘要:}

本文根据对毒品零售罪犯的访谈，讨论了非法的毒品零售交易的不同意义。作者以非结构性访谈的方式，采访 了巴西圣灵州的维多利亚市(Vitoria/ES)和皮乌马市(Piuma/ES) 的刑期届满后被监视居住的毒品零售商贩。作 者发现，这些毒品零售犯人出狱后，由于没有正式工作，没有正常的收入来源，他们很快就会重操旧业，再次 值入毒品零售业。被访者选择再次加入毒品零售的犯罪行业，其原因跟他们初次进入此犯罪行业的原因相同， 都是因为缺少收入稳定的正式工作。我们认为巴西政府对毒品零售业的治理能力低下，执法手段也简单粗暴， 对毒品零售犯罪分子采取关了放，放了再关。这就使得毒品交易日益猖獗。当前，由于COVID-19的大流行， 毒品零售交易也放弃了过去的线下交易，采取了网上订货，商贩送货上门的交易模式，这种情况使得非法毒品 交易更泛滥，更难于被打击。

关键字：毒品贸易；动机；意义；选择性定罪；大规模监禁。 


\section{Introdução}

Segundo dados do levantamento nacional de informações penitenciárias, no ano de 2019, de julho a dezembro, 362.547 pessoas cumpriram pena em regime fechado e 222.558 estiveram em prisão provisória no Brasil (BRASIL, 2019). Do total dos indivíduos inseridos no sistema prisional nacional neste período (cumprimento de pena em regimes fechado, semiaberto ou aberto em ambientes prisionais; prisão provisória em estabelecimentos penais; e aplicação de medidas de segurança), 20,28\% respondia a ação penal por crimes previstos na Lei de Drogas 11.343/06 (BRASIL, 2006).

Tais estatísticas indicam um elevado número de pessoas envolvidas no comércio de drogas que são inseridas anualmente no sistema prisional brasileiro, especialmente na condição de presos provisórios e para cumprimento de penas em regime fechado, resultado de uma política criminal de forte combate a tais práticas, largamente conhecida como "guerra às drogas".

Neste contexto de enfrentamento a tais comportamentos, empreendido de forma preponderante pelas polícias civis e militares, que se encontram na linha de frente desta repressão, graves consequências são advindas, valendo-se destacar o elevado número de mortes ocorridas em intervenções policiais.

De acordo com dados do Fórum Brasileiro de Segurança Pública, 6.220 pessoas foram mortas em decorrência de intervenções policiais no ano de 2018 no Brasil, enquanto 343 policiais civis e militares foram assassinados, sendo que $75 \%$ foram mortos fora de serviço (BUENO; LIMA, 2019).

Tal número, então, que se aproxima de $10 \%$ das mortes violentas intencionais ocorridas em território nacional ano a ano, demonstra uma situação dramática vivenciada pela sociedade brasileira, que se depara com uma elevada perda de vidas humanas em decorrência deste esforço estatal de combate a tais práticas.

Neste contexto, então, nos propusemos realizar uma pesquisa baseada em entrevistas semiestruturadas com indivíduos residentes nas cidades de Piúma/ES e na região da Grande Vitória/ES e envolvidos no comércio de substâncias psicoativas ilícitas e outros delitos relacionados à criminalidade urbana, encontrando-se em regime aberto no momento das entrevistas após determinado período de prisão, com a finalidade de lançar luz e melhor compreender os sentidos e lógicas destas práticas e, a partir dos dados obtidos, refletir a respeito da adequação e proporcionalidade das formas de atuação e enfrentamento, por parte do Estado, do comércio de drogas ilícitas. 


\section{Sentidos atribuídos ao comércio de substâncias psicoativas ilícitas e a lógica do tratamento, pelo estado, de sua ocorrência}

$\mathrm{Na}$ pesquisa realizada foi possível perceber que a entrada no comércio de substâncias psicoativas ilícitas ocorre com uma finalidade lucrativa e, para alguns entrevistados, com o objetivo de aquisição de bens materiais típicos da juventude para a obtenção de gozo e prazer, tais como bebida, festas e sexo.

O entrevistado Leandro ${ }^{1}$ relatou que vendeu drogas por dinheiro e que com o que recebia comprava roupas, bermuda e chinelo porque via terceiros andando "bem arrumados":

Minha opinião sobre essa atividade, era dinheiro, cara. Vendia, pegava o dinheiro, comprava roupa, gastava... Minha vó uma vez chegou pra mim e falou cadê seu dinheiro? Eu falei: Ah, vó, gastei tudo. [...] Ali, tá vendendo ali, você não pensa em mais nada. Só pensa no dinheiro. Enquanto você tá vendo o dinheiro entrando, você não pensa em nada, cara. É só para aquilo [...] (Leandro, Piúma/ES, 18 dez. 2018).

Teotônio afirmou como usava o rendimento do comércio de substâncias psicoativas ilícitas em dois momentos distintos de sua vida. Na época em que começou e era mais jovem e solteiro, o dinheiro que recebia da venda de drogas usava com consumo de drogas, "puta" e bebida:

[...] eu gastava dinheiro com puta, gastava dinheiro em puteiro. Tinha vez que eu pegava as drogas, tinha vez que eu usava. Tinha vez que eu pegava o dinheiro, dava pra... pros outros. Gastava com, com ostentação. Gastava com bebida cara. Cheguei comprar um carro, mas o carro deu problema, aí eu não tinha habilitação, eu abandonei o carro. Já cheguei ter moto (Teotônio, Piúma/ES, 20 dez. 2019).

Em um segundo momento, quando passou a conviver com sua companheira, afirmou:

[...] aí quando comecei construir, aí reboquei por dentro, fiz um telhadinho lá, uma meia água, aí caí pra dentro. Aí coloquei contra-piso e fui reformando devagarinho. [...] aí conforme o dinheiro ia entrando, ia comprando os negocinhos e reformando a casa. [...] igual o que eu sempre falei o sol, o sol nasce pra todos, se eu tô ali no crime ali, eu tava querendo ganhar o meu trocado, não queria mexer com ter guerra, ter briga com ninguém não (Teotônio, Piúma/ES, 20 dez. 2019).

Genilson mencionou, em sua entrevista, que passou comercializar substâncias psicoativas ilícitas porque não tinha dinheiro para comprar alguns bens de consumo, como tênis e chinelo, além de bebida, roupa, sair com mulheres e para andar "bem arrumado" como alguns amigos:

\footnotetext{
${ }^{1}$ A fim de resguardar a identidade dos entrevistados, os nomes utilizados neste artigo para identificá-los são fictícios.
} 
[...] meu pai, quando nós "era" mais novo, ele não ajudava nós em nada não. Só comprava um teniszinho, um chinelo, lá uma vez ou outra... no ano. Minha mãe ficava sempre trabalhando, pra sustentar nós. Nós "era" em sete irmãos, seis irmãos dentro de casa, era em cinco. Era nós cinco. Aí às vezes faltava as coisas. [...] aí via os amigos andando mais arrumado. Aí peguei, "ah, vou andar igualzinho eles também", comecei traficar (Genilson, Piúma/ES, 13 dez. 2018).

Para José Antônio (Piúma/ES, 13 fev. 2019), justificou sua entrada no comércio de substâncias psicoativas ilícitas por "[...] orgia. Orgia, é... e coisas erradas. É, foi mais orgia mesmo, pra poder ostentar coisa que não tinha! Tentar ostentar coisas do outros. Tudo erro da vida. [...]".

Sobre a forma como gastava seu rendimento com o comércio de substâncias psicoativas ilícitas, Roberto (Piúma/ES, 06 fev. 2019) narrou que "[...] O meu negócio era zuar, beber muito. [...] Só pra pagar mesmo e zuar um pouco mesmo. Só pra pagar os outros, dava pra viver. [...] Eu gastava muito. [...] Com mulher e bebida. [...]".

Em resposta à pergunta a respeito dos motivos que o levou a entrar no comércio de substâncias psicoativas ilícitas, Renato (Vitória/ES, 13 set. 2019) respondeu:

[...] dinheiro fácil, né, cara. [...] Acho que uma mera ilusão de uma criança, tipo, de conquistar alguma coisa, ser dono de alguma coisa. Entendeu? Ou ter muito dinheiro, ou ter carro, ou... via um patrão chegando na favela. Com arma. Cheio de mulher, então é isso, entendeu? É uma mera ilusão de um jovem, adolescente, uma criança. [...] Foi já acontecendo, consequentemente, e também por causa de querer ganhar dinheiro, entendeu? Usar droga, gostava muito de usar droga. De curtir um rock, não favela, esses rocks... mas um rock mais socialzinha entre meus caras mesmo, entendeu? Mais isso. Colocar uma cocaína, colocar uma maconha ali. Umas "mulher" também, entendeu? Colocar umas maconhas pra elas, dar um dinheiro, comer e era isso. [...] a finalidade era essa, curtir, curtir! Curtir sem... vamos assim, sem pensar na consequência.

João (Vitória/ES, 16 ago. 2019), ao ser entrevistado, relatou que usava a renda do comércio de substâncias psicoativas ilícitas para usar drogas e comprar roupas de marca, já que seu salário não era suficiente para arcar com esses custos:

[...] por que às vezes eu queria fumar maconha, fumava muito, aí gostava de roupa de marca. Entendeu? Aí o dinheiro não dava. Dinheiro não dava. [...] Eu com dezesseis anos, eu já comecei ter aquela ambição por roupa, essas coisas, entendeu? Dezesseis anos. Aí meu pai e minha mãe não tinha condição de me dar também, entendeu?

Eder (Vitória/ES, 09 ago. 2019) também trouxe a justificativa do desejo de "andar arrumado" para ter entrado no comércio de substâncias psicoativas ilícitas:

Foi quando eu comecei a conhecer essa menina aí, entendeu? que, na verdade, eu tava morando com minha mãe, eu queria ter dinheiro, queria comprar algumas coisas pra mim, que eu via com os outros tendo, entendeu? Queria andar arrumado. Comer alguma coisa melhor, aí eu comecei a mexer com essas coisas erradas. [...] 
é, ter dinheiro, comprar uma moto, que você sabe que de menor não pode ter. Ter um carro, dinheiro no bolso. Sair com as meninas, e as mulher já vem em torno disso aí tudo, entendeu?

João (Vitória/ES, 16 ago. 2019) usava a renda do comércio de substâncias psicoativas ilícitas para usar drogas e comprar roupas "de marca”, já que seu salário não era suficiente para arcar com esses custos:

Por que às vezes eu queria fumar maconha, fumava muito, aí gostava de roupa de marca. Entendeu? Aí o dinheiro não dava. Dinheiro não dava. [...] Eu com dezesseis anos, eu já comecei ter aquela ambição por roupa, essas coisas, entendeu? Dezesseis anos. Aí meu pai e minha mãe não tinha condição de me dar também, entendeu?

Luís (Vitória/ES, 13 set. 2019), questionado sobre a forma com que gastava sua renda desta atividade, respondeu:

Porra, com droga e com festa. [...] Dava droga pros outros, assim. Os amigos, os amigos enche, os amigos né. [...] Padaria. Almoçava em padaria. Jantava em restaurante. [...] Tudo superficial, assim.

Conforme Lyra (2013, p. 75$)$, neste processo de passagem para a vida adulta é possível perceber as etapas da "infância, individuação e autonomia", havendo nesta última fase um período de descobertas que

[...] envolve o adolescente por completo e the revela facetas ocultas e prazerosas de um mundo até então ignorado ou inacessível. Sua trajetória, que se inicia como uma orientação para o futuro na fase infantil, logo se transforma na necessidade presente da complementação da renda familiar e, em seguida, quando de sua independência, parece se concentrar na satisfação do agora (LYRA, 2013, p. 83, grifo do autor).

Nesta fase de autonomia o envolvimento no comércio de substâncias psicoativas ilícitas se apresenta como uma alternativa para financiar o acesso a atividades e bens valorizados pelo contexto habitado pelo jovem, tais como o consumo de drogas lícitas e ilícitas; a frequência a festas; o relacionamento com mulheres; a compra de roupas e acessórios para se vestir da forma apreciada pelos demais jovens de seu convívio; a aquisição de aparelhos celulares, bem que se encontra no topo da escala de bens cuja posse é desejada pelos jovens.

A análise destes achados nos demonstra que o estilo de vida cuja manutenção é pretendida pelo jovem que ingressa no comércio de substâncias psicoativas ilícitas não se distingue de forma significativa daquele que é mantido pelos jovens de classe média, estilo de vida este que é largamente divulgado, incentivado e valorizado pela mídia e plataformas de arte e cultura de massa. 
É então o desejo de alcançar e manter este estilo de vida que impele o jovem de classe baixa para o comércio de substâncias psicoativas ilícitas, eis que os parcos recursos de sua família não permitem o custeio dos mais simples e básicos bens de consumo, como algumas roupas básicas, muito menos a manutenção deste estilo de vida pretendido, que em si não possui nada de excepcional, equivalendo ao padrão de vida de um jovem de classe média.

Com frequência em relação a este jovem há um julgamento por demais severo quanto aos motivos de sua escolha, de que se trata de fato ainda mais grave ter agido motivado pelo desejo de acesso a esses tipos de bens, como se se tratasse de jovens demasiadamente fúteis ou frívolos, quando na verdade agiram exclusivamente com o objetivo de satisfazer os mesmos desejos possuídos pelos demais jovens de classe média, mas que não precisam recorrer a esses meios ilícitos para satisfazer seus interesses.

Há uma menção à “ostentação", conforme dito por Tetônio (Piúma/ES, 20 dez. 2019), do desejo de exibição do acesso a bens de consumo valorizados no contexto em que vivem e na sociedade capitalista de modo geral, citação do desejo de "andar bem arrumado", o que também pode estar ligado a uma demanda por reconhecimento e preenchimento de um orgulho e autoestima próprios profundamente depreciados em seus contextos de vida.

Diversos outros sentidos foram percebidos na pesquisa, no entanto, em relação à prática do comércio de substâncias psicoativas ilícitas, como por exemplo a prática de um pequeno comércio de drogas junto a conhecidos para pagar apenas o custo com o uso de drogas, como foi relatado pelo entrevistado João Cláudio (Piúma/ES, 16 jan. 2019):

Comecei a fumar maconha, estava com quatorze anos, eu estava na escola. Aí com dezoito anos, conheci um amigo... é, amigo entre aspas. Aí ficou aquela relação, você entendeu, senhor? Vem pra cá, compra uma bucha de maconha, daqui a pouco vai comprar mais uma bucha, pegou um pedacinho maior. Aí tirava o dinheiro de fumar, eu comprava, tipo assim, eu comprava meio quilo de maconha, quinhentos reais. Aí eu pegava, tirava aqueles quinhentos reais, fazia aqueles quinhentos reais rapidinho, e o restante eu guardava pra mim fumar, pra não ficar indo de boca em boca comprando, entendeu?

Alguns entrevistados não enveredaram fortemente na prática do comércio de substâncias psicoativas ilícitas, não fazendo deste comércio ilícito seu modo de vida. João Cláudio exercia sua atividade de pescador e com a renda de seu trabalho arcava com suas despesas mensais. O uso de maconha, que prosseguia mesmo depois de condenado por haver comercializado substâncias psicoativas ilícitas e após receber a progressão de regime, era custeado, na época de sua prisão, com o valor do pequeno comércio que fazia entre amigos. Vendia uma parte do que comprava de forma a reaver o valor que pagou e 
consumia o que sobrava da droga. Seu comércio não era armado e não agia associado a quem quer que fosse.

Conforme Zinberg (1984, p. 93, tradução nossa):

Outra questão mencionada por pelo menos $23 \%$ ou um quarto dos sujeitos foi o tráfico (venda de drogas). Os usuários mais experientes lidam uma vez ou outra. Normalmente, isso não é para fins lucrativos (embora muitos tentem obter alguma quantidade grátis para si mesmos), mas para conveniência e solidariedade. Se alguém puder fazer uma boa compra no mundo dos usuários de maconha, é esperado que ele deixe seus amigos entrar na transação. Ele se tornou um revendedor. Sendo revendedor, ele também pode fazer novos conhecidos e desenvolver um certo prestígio.

É comum, então, que o usuário de drogas se envolva no comércio sem um objetivo de lucro, a partir da demanda por acesso às drogas por parte de pessoas de seu convívio. Por possuir mais tempo e experiência de uso e contatos de vendedores, passa a ser uma referência para novos usuários. Isso pode fazer com que ingresse mais fortemente no comércio, que foi o caso do entrevistado Luís, jovem de classe média de Vitória/ES que passou a comercializar substâncias psicoativas ilícitas por possuir contatos com fornecedores e em razão da demanda por uso em seus grupos de convivência, ou permanecer vendendo apenas para conhecidos para custear seu uso, o que ocorreu com João Cláudio.

O entrevistado Sílvio (Piúma/ES, 30 jan. 2019) relatou que, após se separar, passou a conviver com um grupo de mineiros que se mudou para seu bairro e que realizava comércio de substâncias psicoativas ilícitas. Como convivia com o grupo não precisava pagar para consumir, e, em razão de ser conhecido no bairro, encaminhava pessoas para comprar drogas com aquele grupo como uma espécie de contrapartida pelo uso gratuito e compartilhado. Não lucrava diretamente ao auxiliar no comércio, salvo ao não precisar pagar pelo que consumia, nem tampouco pegava em armas ou envolvia crianças e adolescentes em sua prática.

Alguns entrevistados relataram que o comércio de substâncias psicoativas ilícitas também tinha a função de substituir o trabalho lícito em razão do desemprego e permitir que auferisse ganhos para fazer frente às despesas mais básicas. Teotônio (Piúma/ES, 20 fev. 2019), ao mencionar que "o sol nasce para todos" e que "não queria mexer com ter guerra, ter briga com ninguém", informa que a renda do comércio de substâncias psicoativas ilícitas era gasta também para construir a casa que morava com sua companheira, indicando uma ampla variedade de sentidos para a ocorrência do comércio de drogas.

Genilson (Piúma/ES, 13 fev. 2018), ao mencionar que "quando era mais novinho não 'pegava' ninguém na escola" e que quando ingressou no comércio de substâncias 
psicoativas ilícitas "começou a fluir", indica como a entrada no comércio de substâncias psicoativas ilícitas também tem um sentido para os jovens relacionado à sua transição para a vida adulta e afirmação de sua masculinidade.

Ao permitir uma maior aproximação com garotas, o comércio de substâncias psicoativas ilícitas tem para esses jovens um sentido ligado ao aumento de sua autoestima e orgulho próprios, especialmente em razão de habitarem um contexto de baixa probabilidade de reforço desses atributos, como a pobreza e as faltas materiais experimentadas, pequena possibilidade de sucesso profissional, melhora de padrão de vida e status social.

O entrevistado Renato (Vitória/ES, 13 set. 2019) relatou algo nesse sentido, de que a entrada no comércio de substâncias psicoativas ilícitas se tratou de uma "mera ilusão de uma criança", de "conquistar alguma coisa, ser dono de alguma coisa", de "ter muito dinheiro", carro etc. Relata que "via um patrão chegando na favela", "com arma", "cheio de mulher". Para ele, então, o comércio de substâncias psicoativas ilícitas era uma forma mais rápida de permitir o gozo de um estilo de vida desejado, a partir de um referencial que se encontrava em seu contexto e que, em razão disso, se apresentava para ele possível e alcançável.

Além de diversos sentidos, várias funções distintas também podem ser exercidas por aqueles que ingressavam na estrutura do comércio de substâncias psicoativas ilícitas propriamente dita, compondo de alguma forma uma organização criminosa. Dentre os entrevistados Luís afirmou que era "dono" de seu próprio comércio de drogas, exercendo a venda junto a jovens de classe média e alta da Grande Vitória e chegando a alugar um apartamento para esta atividade. Júlio (Vitória/ES, 16 ago. 2019) afirmou que era "gerente" da boca de fumo onde trabalhava e que frequentemente andava armado para exercer a cobrança daqueles subordinados a ele no exercício desta atividade, que em regra trabalhavam como "vapores", aqueles que faziam a venda direto ao usuário, como Leandro e Genilson; há também a função do "avião", aquele que se desloca para buscar a droga junto a fornecedores, função que em algum momento foi desempenhada por Teotônio; "olheiro", aquele que tem a função de vigiar a boca de fumo e avisar caso a polícia se aproxime, atividade que também fora desempenhada por José Antônio.

A atividade desempenhada, por exemplo, por João Cláudio e Wilson (Piúma/ES, 12 dez. 2018) diverge das funções acima mencionadas, eis que eles compravam determinada quantidade de drogas, já pagando de forma antecipada, o que em regra não é feito pelo "vapor", que presta contas posteriormente, e após repassavam parte da droga adquirida para pessoas de seu convívio, recebendo de seus "sócios do uso" ou o valor total que 
despendeu, ficando isento de despesa com o uso, ou apenas o valor equivalente àquela parte da droga entregue. Tecnicamente, no entanto, ambos estão alcançados pela descrição do art. 33 da Lei 11.343, já que nem sempre havia o uso compartilhado para desclassificar a conduta para aquela descrita no art. $33, \S 3^{\circ}$ da Lei 11.343 , que, apesar de ter pena mais branda, não deixa de ser crime (BRASIL, 2006).

Conforme Boiteux et al (2009, p. 42):

Por outro lado, há de se ressaltar que a forma de organização desse tipo de comércio não se dá de forma uniforme, pelo contrário, é adaptado às configurações locais. Apurou-se, ainda, que a organização interna, especialmente do varejo, segue mecanismos específicos que diferem, muitas vezes, de um estado para outro da federação, tanto pela forma de atuação dos seus atores como quanto aos tipos de substância comercializada.

Nosso trabalho, então, indica a ampla variedade das formas da prática do comércio de substâncias psicoativas ilícitas, alterando-se não apenas as funções desempenhadas pelos envolvidos na estrutura desta atividade, como também as dinâmicas e os sentidos para sua prática, ocorrendo para o custeio de bens e atividades comumente ligadas a qualquer grupo de jovem; para o exercício de uma atividade remunerada em uma situação de desemprego e para o custeio das despesas cotidianas básicas; como meio de reforço da masculinidade e para seguir o exemplo de pessoa bem sucedida na comunidade a partir de determinados valores compartilhados naquele local; para sustentar o uso de drogas etc.

O que se percebe, então, é que os motivos que levam ao engajamento no comércio de substâncias psicoativas ilícitas não variam das razões que conduzem as pessoas ao envolvimento em atividades não consideradas desviantes, como o exercício de trabalho lícito, a participação em cursos profissionalizantes e atividades de ensino etc.

A diferença é que circunstâncias de faltas materiais e profunda privação, aliadas à participação em contextos onde práticas ilícitas ocorrem de forma sistemática e disseminada, levam determinados indivíduos a se envolverem nesses comportamentos pelos mesmos motivos e para atingir os mesmos objetivos que pessoas que compõem grupos sociais distintos se envolvem em outras atividades aceitas socialmente e não consideradas desviantes. Para Boiteux et al. (2009, p. 39):

Desta forma, a atividade econômica ligada ao tráfico de drogas no Brasil é fortalecida pela falta de perspectiva, desemprego e exclusão, o que leva jovens e agricultores ao negócio da droga, que mesmo ilícito, ou talvez por isso, permite o aumento do lucro e dá oportunidades de vida a pessoas sem acesso ao mercado de trabalho formal, e ainda paga salários superiores ao mercado formal. $\mathrm{Na}$ análise da situação brasileira, a face mais perversa do desemprego se caracteriza pelo fato de que "o contingente anual de criminosos é engrossado pela massa de jovens que 
jamais ocuparam uma vaga no mercado formal de trabalho", que constituem o grupo social mais vulnerável a ser utilizado pelo tráfico.

Analisando a natureza propriamente dita desses comportamentos podemos constatar que há um tratamento desproporcional do Estado quanto a maioria desses delitos, criminalizados de forma seletiva.

Enquanto condutas como a sonegação fiscal são tratadas de forma absolutamente parcimoniosa pelo Estado, o comércio de substâncias ilícitas, mesmo que sem a posse ou o porte de arma, a prática de violência, o envolvimento em organizações criminosas ou a participação de crianças e adolescentes, gera uma resposta estatal via de regra demasiadamente severa.

Em seu texto, insiste-se na utilização de termos bélicos, como "guerra às drogas",
"combate" aos traficantes, repressão e "eliminação" nas leis penais. A associação
explícita entre o tráfico ilícito de drogas e as "organizações criminosas" também
reforça esse modelo, pois se considera que estas teriam como objetivo "minar as
economias lícitas e ameaçar a segurança e a soberania dos Estados", além de
"invadir, contaminar e corromper as estruturas da Administração Pública...". O apelo
à guerra era emocional e mesmo irracional. Foi com base neste último instrumento
de 1988 que se internacionalizou de forma definitiva a política americana de "guerra
às drogas" (BOITEUX et al., 2009, p. 19).

A legislação brasileira, então, internalizando a política americana de "guerra às drogas" e considerando hedionda a conduta de comercializar substância entorpecente independentemente da consideração do contexto de prática do crime, eis que os parâmetros do art. 33, $\S 4^{\circ}$ da Lei. 11.343 (BRASIL, 2006), que permite a redução da pena e o afastamento do caráter hediondo do crime, são excessivamente subjetivos para permitir seu adequado reconhecimento, tem levado ao aprisionamento indivíduos com baixo envolvimento em práticas criminais, expondo-os a uma maior influência em favor de crime, o que também foi possível perceber em nossa pesquisa, que indicou uma forte "associação diferencial"2 (MATSUEDA, 1982) durante o cumprimento da pena. Houve indivíduos, a exemplo de Tião, que somente passaram a se envolver diretamente no comércio de substâncias psicoativas ilícitas após o período em que permaneceram presos.

Rosa (2014, p. 293) vê no atual formato jurídico-legal de definição acerca de quais condutas devem ser consideradas tráfico de drogas o fenômeno de "criminalização da pobreza":

\footnotetext{
2 Para Matsueda (1982, p. 489, tradução nossa), "Definições favoráveis e desfavoráveis (padrões de comportamento) são ponderadas por frequência, duração, prioridade e intensidade. Assim, os padrões de comportamento apresentados com maior frequência, apresentados por mais tempo, apresentados mais precocemente na vida, e apresentados por uma fonte de maior prestígio, terão mais peso no processo produzindo comportamento delinqüente ou não-delinquente (associação diferencial)".
} 


\begin{abstract}
Tendo em vista que a legislação brasileira não define claramente a quantidade exata de substâncias psicoativas ilícitas apreendidas pela polícia federal na atribuição do crime denominado de tráfico de drogas, constato a validade da tese elaborada por certos pesquisadores da criminologia crítica fundamentada na ideia de que a criminalização da pobreza pode ser verificada como um fenômeno mundial; e que, no Brasil, acaba ganhando destaque, sobretudo, através da "guerra contra as drogas", na qual a maior parte da população encaminhada para o sistema carcerário compartilha uma cultura muito próxima - inclusive permeada pelo consumo de substâncias psicoativas tidas como ilegais.
\end{abstract}

Além do apontado fenômeno da "criminalização da pobreza" (ROSA, 2014), que permite uma incriminação preventiva de significativa parcela da população brasileira, majoritariamente negra e localizada na base da pirâmide social, a política de 'guerra às drogas', largamente defendida e estimulada, torna a relação "polícia x comerciantes de drogas" altamente tensa e conflituosa, o que leva à um elevado número de mortes de ambos os lados, além de favorecer a corrupção policial, pois policiais mal remunerados passam a entrar em contato estreito com os comerciantes de substâncias psicoativas ilícitas com algum nível de lucro e dispostos a assumir o custo da corrupção policial para manter sua atividade, encontrando espaço em tal prática com o sucateamento e baixo investimento na atividade policial. De acordo com Boiteux et al. (2009, p. 43):

\begin{abstract}
A seletividade do sistema penal foi confirmada na presente pesquisa. No caso dos crimes de droga, conforme analisa Álvaro Pires, não há um desvio conflitual entre um ato e uma vítima, sendo a ação pró-ativa das autoridades (flagrantes e incursões policiais) que produzem uma série de efeitos perversos no próprio funcionamento do sistema jurídico, como o problema da corrupção, que constitui a forma de intervenção da polícia no limite da legalidade.
\end{abstract}

Conforme as autoras, as polícias atuam de forma seletiva e com frequência passam a se associar aos comerciantes de substâncias psicoativas ilícitas, conforme relatado por diversos entrevistados, que afirmaram que chegavam a pagar valores para policiais a fim de exercerem sua atividade sem interferência.

A política de "guerra às drogas", instituída e largamente defendida por variados setores da sociedade, não somente favorece a corrupção de policiais, como torna a relação existente entre a polícia e os comerciantes de drogas ilícitas altamente tensa e violenta. Um achado interessante em nossa pesquisa é que, dentre os entrevistados que relataram informações negativas em relação à polícia, a maioria destes eram pessoas envolvidas com o comércio de substâncias psicoativas ilícitas, enquanto aqueles que cometiam assaltos em regra tinham uma opinião positiva da polícia militar.

Na pesquisa surgiram elementos contundentes em relação à forma de atuação da polícia militar, com relatos variados de práticas de corrupção e atos de violência por 
militares, sendo possível perceber que tais relatos via de regra surgiram de pessoas envolvidas com o comércio de substâncias psicoativas ilícitas, enquanto aqueles que se envolveram com roubo tinham poucos relatos negativos em relação à polícia militar.

Foi nítido como as informações mais negativas em relação à polícia militar se avolumavam quando a entrevista ocorria com alguém que se envolveu no comércio de substâncias psicoativas ilícitas, enquanto tais elementos escasseavam quando se tratava de alguém que praticou apenas assaltos. Tais diferenças podem se explicar exatamente em razão dessa política de "guerra às drogas" assumida pelo governo e pelas polícias, que faz com que os policiais passem a perseguir e abordar com frequência suspeitos de tráfico, enquanto os assaltantes são perseguidos e presos apenas quando o ato é flagrado. "Praticantes do 157" não são constantemente abordados pela polícia militar pelo simples fato de que não há como identificá-los tão facilmente, já que seus crimes não são limitados territorialmente. Ao contrário, eles saem de seu território para praticá-los e, quando são presos em flagrante, com frequência não questionam a atuação da polícia, que agiu para coibir e prevenir um crime que nem mesmo os envolvidos justificam logicamente sua prática.

Foi possível perceber que, enquanto o envolvido no comércio de substâncias psicoativas ilícitas exerce essa atividade de forma rotineira e em um território estabelecido, o recurso ao assalto ocorre para vários envolvidos de forma excepcional. Fabiano (Piúma/ES, 21 fev. 2019) relatou que assaltou ao perceber que trocou um celular recebido de seu patrão por crack; Sander (Piúma/ES, 19 dez. 2018) contou que assaltou porque teve seu celular furtado em sua casa; José Antônio disse que praticou um assalto ao perceber que gastou o pouco dinheiro que tinha para sua família em um baile funk; outros entrevistados relataram que recorreram ao assalto em razão de uma perda de carga de droga, necessitando de dinheiro imediato para pagar ao gerente da boca pela perda que sofreram.

Não se percebeu, então, o assaltante contumaz nos relatos obtidos, diferentemente do praticante do comércio de substâncias psicoativas ilícitas, que realiza o comércio com frequência e em um local delimitado, o que o torna alvo frequente de incursões e operações por parte da polícia militar, que passa a agir de forma muitas vezes a incriminá-lo preventivamente, já que pode se tratar de um mero usuário ou de alguém que abandonou o comércio de substâncias psicoativas ilícitas e que passa a ser constantemente tido como traficante e abordado como tal, o que se constitui no processo de sujeição criminal (MISSE, 2010). ${ }^{3}$

\footnotetext{
${ }^{3}$ Para Misse (2010), o sujeito é resultado de uma estrutura de poder, havendo espécies de subjetivação que formam um sujeito não revolucionário, não democrático e não igualitário, como o sujeito largamente conhecido
} 
É importante registrar que quando afirmamos baixa tensão evidentemente que não excluímos as constantes trocas de tiro existentes em momentos de perseguição logo após o cometimento de assaltos. $\mathrm{O}$ assalto e a consequente perseguição, quando ocorrem, são evidentemente momentos altamente tensos quando o assaltante opta por fugir ou reagir contra os policiais, podendo causar inclusive morte de ambos os envolvidos na situação.

Quando mencionamos baixa tensão nos referimos à relação existente entre os mesmos, tanto antes do assalto como após. Preso em flagrante, via de regra o assaltante reconhece o equívoco de sua conduta e não guarda, em relação aos policiais, elevado grau de hostilidade, assim como os policiais não o incriminam previamente com abordagens constantes e rotineiras. Diversa, entretanto, é a situação do comerciante de substâncias psicoativas ilícitas, constantemente abordado no local onde vive e exerce sua atividade de comércio de drogas, sentindo-se perseguido pelo Estado em seu local de residência por uma atividade que no limite não considera significativamente errada ou grave. Trata-se da venda de substâncias cuja ilegalidade é questionável quando ocorre para maiores e capazes, pessoas que tem sua capacidade de entendimento e discernimento preservadas e espontaneamente adquirem substâncias que desejam usar, diferentemente do assalto, conduta cuja ilicitude concordam e que em regra apenas praticam em situações excepcionais, compreendendo como correta e adequada a conduta da polícia de prendêlos e da justiça de condená-los.

Todo esse contexto indica equívocos na forma como o Estado trata o comércio de drogas. Se de um lado o tráfico armado; a ação do fornecedor internacional ou interestadual de drogas; o comércio que envolve crianças e adolescentes merece severa punição, aquela venda individual para maiores e capazes sem a prática da violência ou o uso de arma não encontra justificativa para o tratamento demasiadamente rigoroso que lhe é dado pelo Estado. Assim, conforme Boiteux et al. (2009, p. 44) "[...] se conclui estar o campo jurídico alienado da realidade do fenômeno do comércio de drogas ilícitas". Para essas autoras,

[...] não há um desvio conflitual entre um ato e uma vítima, sendo a ação pró-ativa das autoridades (flagrantes e incursões policiais) que produzem uma série de efeitos perversos no próprio funcionamento do sistema jurídico, como o problema da corrupção, que constitui a forma de intervenção da polícia no limite da legalidade (BOITEUX et al., 2009, p. 43).

como "bandido", resultado de um processo de acumulação social da violência decorrente da "[...] interpelação da polícia, da moralidade pública e das leis penais". 
Este comércio, então, individual, não violento e desarmado não possui razões intrínsecas que justifiquem a forma demasiadamente severa que é tratado pelo Estado, com a ressalva daquela perspectiva moral que também está na base da criminalização do uso de drogas. Este pequeno comerciante, então, conforme pesquisa das autoras citadas, apesar de representar percentual significativo dos condenados por tráfico de drogas, tem recebido tratamento semelhante ao dado ao traficante armado, chefe de organização criminosa ou àquele grande fornecedor e transportador de elevada quantidade de entorpecente.

A partir da análise dos achados obtidos é possível perceber que faltas materiais se constituem em um dos principais fatores para motivar o envolvimento no comércio de substâncias psicoativas ilícitas. Quando o entrevistado se encontrava em um contexto em que suas necessidades materiais eram supridas, tendiam menos a ingressar nesta atividade, a exemplo de João Cláudio, que relatou que caso não tivesse seu trabalho à época dos fatos certamente teria "entrado mais pesado" no comércio, e Kennedy, que afirmou nunca ter se envolvido no comércio de substâncias psicoativas ilícitas e que sempre teve "as coisas", "um dinheiro", que sua mãe sempre lhe dava "tudo", não precisando pagar sequer água e luz quando passou a viver com sua companheira. Sua mãe dizia, segundo ele: "não quero dinheiro seu não. Dinheiro seu, que você fizer, é pra você, pra comprar suas coisas" (Kennedy, Piúma/ES, 31 jan. 2019).

Foi bastante interessante comparar na pesquisa a realidade do entrevistado Luís, comerciante de substâncias psicoativas ilícitas da classe média de Vitória e residente em um bairro desta classe, e o contexto do exercício desta atividade, a título de exemplo, por Renato, morador de localidade periférica na capital. Enquanto o primeiro relatou nunca ter sido abordado pela polícia e nunca ter tido ou manuseado arma de fogo, chegando a alugar um apartamento para manter em depósito as drogas que vendia, ter pessoas trabalhando para si e ter sido preso apenas ao se deslocar a Manaus de avião para trazer cocaína para revenda, o segundo exercia esta atividade armado, já matou usuários por dívida de drogas e relatou casos de policiais corruptos, que recebiam dinheiro para tolerar sua atividade ilegal e que plantavam drogas e armas para incriminar desafetos.

A mesma conduta, então, praticada em contextos sociais tão distintos, gera formas de intervenção do Estado diversas, violenta e corrupta em um caso e pontual e isolada em outro.

Não se deve desconsiderar que existem contextos distintos e que, no caso da realidade de Renato, possivelmente está presente uma sociabilidade profundamente 
impregnada de violência (SILVA, 1999), ${ }^{4}$ o que não ocorre no caso de Luís. A questão é em que medida o Estado, criminalizando exageradamente certas condutas de moradores da periferia, incriminando-os preventivamente e agindo de forma corrupta e violenta mesmo perante pessoas pouco envolvidas em ilícitos, contribui para o aprofundamento e manutenção desta cultura de violência estabelecida e socializada nesses contextos.

\section{Considerações finais}

Procuramos dar voz em nosso trabalho àqueles que se envolveram em crimes, especialmente o comércio de substâncias psicoativas ilícitas e crimes patrimoniais, à semelhança do trabalho desenvolvido por García-Reyes (2018, p. 55, tradução nossa) tendo como objeto drug trafficking violence (DTV):

[...] a literatura ainda é silenciosa em relação ao 'discurso do narco': quais são as condições discursivas que permitem a produção e reprodução de práticas de DTV? Este estudo propõe uma nova abordagem crítica à nossa compreensão da DTV, identificando e analisando como o discurso do narco é produzido e reproduzido nas narrativas dos trinta e três ex-narcos entrevistados para este projeto.

Esta autora, à semelhança do trabalho desenvolvido por nós, ressalta a perspectiva dos perpetradores. Entrevistar envolvidos e ouvi-los permite compreender sentidos e lógicas por trás de suas práticas ilícitas, as razões que os levaram a essas escolhas e os aspectos de suas trajetórias de vida que se mostraram determinantes para esse envolvimento, além de poder subsidiar a implementação de políticas públicas elaboradas a partir da lógica dos que incorrem nessas práticas, podendo, assim, se apresentar mais eficientes.

Então, a partir desta metodologia, uma questão interessante que surgiu na pesquisa a respeito dos sentidos atribuídos ao comércio de substâncias psicoativas ilícitas foi o fato de que o envolvimento nesta atividade se dá, para o jovem, em grande medida em razão de sua percepção de que o mercado formal e legal está fechado para as crianças e adolescentes, sendo o mercado ilegal uma alternativa para obtenção de uma renda que permitirá o acesso a bens de consumo desejáveis na fase da adolescência.

\footnotetext{
${ }^{4}$ De acordo com Silva (1999), em razão do advento deste novo referencial cultural violento, o próprio sujeito criminoso não mais veria sua conduta como desviante, mas como algo normal dentro de seus referenciais e parâmetros pessoais. Para o autor "[...] a criminalidade violenta organizada pode ser vista como a ponta de um iceberg. Ela indicaria transformações culturais imensamente profundas e a formação de uma sociabilidade radicalmente nova que a teoria social tem muita dificuldade de apreender [...]" (SILVA, 1999, p. 120), afirmando, ainda, que a "[...] organização contemporânea da criminalidade corresponde à implantação da violência generalizada como base de um novo ordenamento social [...]" e que mesmo "[...] no cenário mais positivo de aprimoramento do quadro político-econômico seremos obrigados a presenciar a institucionalização da criminalidade violenta [...]" (SILVA, 1999, p. 123).
} 
A falta de acesso de jovens ao mercado regular, sob uma falsa impressão de que o exercício de atividade laboral é vedado ao jovem, aparentemente se constitui, pelo que foi possível perceber na pesquisa, em um relevante fator a impulsioná-lo para o comércio de substâncias psicoativas ilícitas. Há um grande desconhecimento, por exemplo, acerca da figura do jovem aprendiz, assim como é pouco fiscalizada a aplicação da Lei $n^{\circ} 10.097$ (BRASIL, 2000). ${ }^{5}$

Tais jovens, então, vivendo em ambientes materialmente precarizados e impulsionados pelo desejo de acesso a certos bens de consumo veem no comércio de substâncias psicoativas ilícitas a principal alternativa para suprir suas necessidades típicas da juventude, havendo pouco conhecimento e acesso às vagas de aprendizes, que muitas vezes sequer são abertas. Muitos entrevistados relataram que o comércio de substâncias psicoativas ilícitas foi a única alternativa que encontraram para financiar o acesso a bens de consumo que desejavam na entrada da juventude.

Assim, pesquisas relacionando estes desejos, o acesso ao mercado de trabalho regular e o efetivo cumprimento da legislação que obriga que empresas ofertem vagas de aprendizes (Lei $n^{\circ} 10.097$, BRASIL, 2000), assim como a publicidade a respeito destas vagas, pode se mostrar interessante sob a perspectiva das razões que impelem o jovem ao comércio de substâncias psicoativas ilícitas.

Nosso trabalho também permitiu problematizar o que de fato são "bens de primeira necessidade" para uma juventude periférica, já que é comum que motivações como "adquirir tênis, celular, roupas" sirvam para justificar uma consideração mais negativa a respeito de atos praticados por jovens infratores quando na realidade estes jovens enveredaram por tais práticas pelos mesmos desejos compartilhados pela maioria dos jovens de outras classes sociais. Como indicado pela pesquisa, trata-se, em verdade, apenas de um desejo de pertencimento, de reconhecimento, de satisfação de demandas que, para esta juventude contemporânea, são consideradas "bens de primeira necessidade", até porque esta definição é socialmente construída e compartilhada.

A pesquisa também nos permitiu perceber como a violência com frequência se constitui em uma espécie de "fetiche às avessas" que serve de sustentáculo para a

\footnotetext{
${ }^{5} \mathrm{O}$ art. 429 da Lei 10.097 dispõe que os "[...] estabelecimentos de qualquer natureza são obrigados a empregar e matricular nos cursos dos Serviços Nacionais de Aprendizagem número de aprendizes equivalente a cinco por cento, no mínimo, e quinze por cento, no máximo, dos trabalhadores existentes em cada estabelecimento, cujas funções demandem formação profissional" (BRASIL, 2000, art. 429), definindo que qualquer adolescente maior de 14 (catorze) anos pode ser contratado como aprendiz.
} 
continuidade de uma política de segurança pública que em verdade significa uma criminalização da população pobre e periférica.

Evidentemente que a violência é um problema real e que atinge milhares de pessoas, praticado por muitos agentes envolvidos no comércio de substâncias psicoativas ilícitas. Ela é, entretanto, sobre dimensionada não quanto à sua gravidade quando ocorre, mas em relação à sua extensão e frequência com que ocorre levando-se em consideração a totalidade deste delito praticado em território nacional.

Fala-se da violência como se ela fosse praticada por todos os envolvidos no comércio de substâncias psicoativas ilícitas, quando, em verdade, e a pesquisa nos indicou isso, ela ocorre possivelmente de forma excepcional e por parte da minoria destes indivíduos.

Analisar, então, se de fato a violência se constituiu em uma espécie de "fetiche às avessas", o grau de frequência e extensão de sua ocorrência em comparação com o quantitativo de delitos de tráfico de drogas efetivamente ocorridos pode se constituir em uma pesquisa interessante para uma espécie de "redimensionamento da prática da violência", além de permitir uma reflexão sobre a real gravidade de parcela significativa do comércio de substâncias ilícitas praticado e a respeito da adequada forma de o Estado lidar com este problema.

\section{Referências}

BOITEUX, Luciana et al. (Coord). Sumário Executivo Relatório de Pesquisa "Tráfico de Drogas e Constituição". Série Pensando o Direito, Rio de Janeiro/Brasília, n. 1, p. 14-121, jul. 2009. Disponível em: http://pensando.mj.gov.br/wpcontent/uploads/2015/07/01Pensando_Direito3.pdf. Acesso em: 25 jan. 2020.

BRASIL. Presidência da República. Casa Civil. Subchefia para Assuntos Jurídicos. Lei $n^{\circ}$ 10.097, de 19 de dezembro de 2000. Altera dispositivos da Consolidação das Leis do Trabalho - CLT, aprovada pelo Decreto-Lei $n^{\circ}$ 5.452, de $1^{\circ}$ de maio de 1943. 2000. Disponível em: http://www.planalto.gov.br/ccivil_03/leis//10097.htm. Acesso em: 12 maio 2020.

BRASIL. Presidência da República. Casa Civil. Subchefia para Assuntos Jurídicos. Lei $n^{\circ}$ 11.343, de 23 de agosto de 2006. Institui o Sistema Nacional de Políticas Públicas sobre Drogas - Sisnad; prescreve medidas para prevenção do uso indevido, atenção e reinserção social de usuários e dependentes de drogas; estabelece normas para repressão à produção não autorizada e ao tráfico ilícito de drogas; define crimes e dá outras providências. 2006. Disponível em: http://www.planalto.gov.br/ccivil_03/_ato2004-2006/2006/lei/l11343.htm. Acesso em: 21 jun. 2020. 
BRASIL. Ministério da Justiça e Segurança Pública. Departamento Penitenciário Nacional. Levantamento nacional de informações penitenciárias. 2019. Disponível em: https://app. powerbi.com/view?r=eyJrljoiZTIkZGJjODQtNmJIMi00OTJhLWFIMDktNzRINmF kNTMOMWI3liwidCI6ImViMDkwNDIwLTQ0NGMtNDNmNy05MWYyLTRiOGRhNmJmZThl MSJ9. Acesso em: 11 nov. 2020.

BUENO, Samira; LIMA, Renato Sérgio de (Coord.). Anuário Brasileiro de Segurança Pública. 2019. Fórum Brasileiro de Segurança Pública, ano 13, 2019. Disponível em: http://www.forumseguranca.org.br/wp-content/uploads/2019/09/Anuario-2019-FINALv3.pdf. Acesso em: 16 maio 2020.

LYRA, Diogo. A república dos meninos: juventude, tráfico e virtude. Rio de Janeiro: FAPERJ, 2013.

MATSUEDA, Ross. L. Testing Control Theory and Differential Association: a casual modeling approach. American Sociological Review, v. 47, n. 4, p. 489-504, Aug. 1982. https://doi.org/10.2307/2095194

MISSE, Michel. Crime, sujeito e sujeição criminal: aspectos de uma contribuição analítica sobre a categoria "bandido". Lua Nova: Revista de Cultura e Política, n. 79, p. 15-38, 2010. https://doi.org/10.1590/S0102-64452010000100003

GARCÍA-REYES, Karina Guadalupe. Poverty, gender and violence in the narratives of former narcos: accounting for drug trafficking violence in Mexico. 2018. Tese (Doutorado em Sociologia) - School of Politics, Sociology and International Studies, University of Bristol, Bristol, 2018. Disponível em: https://researchinformation.bris.ac.uk/en/studentTheses/poverty-gender-and-violence-in-the-narratives-offormer-narcos. Acesso em: 12 jun. 2020.

ROSA, Pablo Ornelas. Drogas e a governamentalidade neoliberal: uma genealogia da redução de danos. Florianópolis: Insular, 2014.

SILVA, Luiz Antônio Machado da. Criminalidade violenta: por uma nova perspectiva de análise. Revista de Sociologia e Política, n. 13, p. 115-124, nov. 1999. https://doi.org/10.1590/S0104-44781999000200009

ZINBERG, Norman Earl. Drug, set, and setting. Binghamton: Vail-Ballou Press, 1984. 